\title{
Gestão da Política de Assistência Social: o lugar da vigilância socioassistencial
}

Social Assistance Policy Management: The place of social assistance surveillance

\author{
Maria Luiza Amaral Rizzotti* \\ Maria do Socorro Souza Vieira** \\ Marinalva Conserva***
}

\begin{abstract}
Resumo
O presente artigo se inscreve entre os estudos sobre gestão de políticas sociais, tendo como objetivo analisar o aprimoramento do Sistema Único de Assistência Social (SUAS), especialmente a implementação da vigilância socioassistencial na esfera estadual. 0 processo metodológico e analítico se pautou pela circunscrição da gestão com dimensão política e técnica, desenhada pelo contexto histórico, econômico e social. Foram considerados os princípios e diretrizes do modelo republicano, democrático, descentralizado e universal preconizados na Constituição Federal de 1988. A base analítica, teve como foco a relação da instância estadual com os municípios incorporando a institucionalidade e as definições que envolvem responsabilidades advindas do pacto federativo. Trata-se de uma pesquisa de caráter qualitativo e estudo de caso, cujo lócus está posto na Secretaria de Estado de Desenvolvimento Humano da Paraíba, que congrega a gestão do Sistema Único de Assistência Social.
\end{abstract}

Palavras Chave: Gestão. Assistência social. Vigilância socioassistencial.

\begin{abstract}
This article is part of the field of studies on social policy management, with the objective of analyzing the improvement of the Unified Social Assistance System (SUAS), especially the implementation of Social Assistance Surveillance at the level of Brazilian states. The methodological and analytical process was guided by the circumscription of management process was with a political and technical, designed by the historical, economic and social context, understanding. It also, considered the principles and guidelines of the republican, democratic, decentralized and universal framework, as recommended by the Federal Constitution of 1988. In addition to this analytical basis, the relationship of the bureaucratic body of Brazilian states with the municipalities was also considered with regard to institutionality and the definitions that involve the responsibilities arising from the federative pact. It is a qualitative research and case study, whose locus was the State Secretariat for Human Development of Paraiba, which brings together the management of the Unified Social Assistance System.
\end{abstract}

Keywords: Management. Social assistance. Social Assistance surveillance.

\footnotetext{
* Pesquisadora Visitante (CNPq/FAPESq) Universidade Federal da Paraíba (UFPB

** Pós-Graduação em Serviço Social da Universidade Federal da Paraíba

*** Professora Titular do Departamento de Serviço Social e do Programa de Pós-Graduação em Serviço Social da Universidade Federal da Paraíba (UFPB)
} 


\section{Introdução}

A configuração das políticas sociais foi demarcada, ao longo da história, por diferentes dimensões que se ancoram nas esferas políticas, econômicas e sociais adensadas na relação entre o Estado e a sociedade civil. Tanto os estudos que se dedicam aos fundamentos das políticas sociais, como os que abordam seu cotidiano no âmbito da gestão e das provisões têm como pressuposto o aprofundamento do modelo democrático e o avanço das lutas sociais, assim como as opções do modelo de desenvolvimento econômico. Desse modo, mesmo que o conteúdo do estudo aqui apresentado se concentre no tema da vigilância socioassistencial se entrelaça ao papel das políticas sociais na sociedade capitalista, evocando a presença do Estado e sua responsabilidade na garantia da proteção social.

Outra lente importante se refere à ruptura com o modo tradicional e hierarquizado de gerir as políticas sociais, reconhecendo a importância da destreza na capacidade de mudança e de aprimoramento. Além disso, há que se reconhecer o papel do Estado, marcado, tanto pelo conservadorismo patrimonialista, como pelo descompromisso com a proteção social balizada, não apenas do modelo liberal (adotado da Europa dos anos 70 e imposto ao mundo latino-americano), mas também pela característica particular da elite brasileira, sem compromisso com a justiça social e com a democracia (FERNANDES, 1975). O fundamento ideológico que sustenta essa elite e que, recorrentemente toma o Estado de assalto, não se dissipou, ao contrário, tem se mostrado cada vez mais feroz na disputa do fundo público e, nos últimos dois anos ${ }^{1}$, vem tensionando, ainda mais, com os valores discriminatórios e princípios conservadores quanto no seu modo de operacionalizar as políticas sociais.

Esse caldo que mescla as determinações econômicas, sociais, políticas e culturais demarcou, ao longo da história, as políticas sociais nesse país, com conformações seletivas, centralizadoras e autoritárias. Daí a importância da quebra de paradigmas erigidos na Carta Constitucional em vigor, resultante de lutas sociais, com bandeiras de

\footnotetext{
${ }^{1}$ Vale destacar que entre os anos de 2003 a 2016, houve importantes iniciativas no sentido de contemplar o protagonismo de movimentos sociais e suas lutas por avanços civilizatórios nas políticas sociais, sobretudo no que concerne ao reconhecimento da desigualdade e vulnerabilidade para diferentes segmentos e territórios.
} 
diferentes correntes políticas que refletiram na institucionalidade das políticas sociais. A sua maior marca recai na ampliação dos direitos sociais e na proteção que impulsionou um desenho constitucional representativo da instauração do Estado Social. Todavia, mesmo com o avanço da autorização legal, ainda perdura a constante luta entre a tradição minimalista, privativista e burocratizada na implementação das políticas públicas, mantendo-se latente a disputa, tanto na dimensão política, como operacional.

Dentre as muitas disputas está a necessidade de defender os sistemas públicos e universais de gestão, como os SUS (Sistema Único de Saúde) e o SUAS (Sistema Único de Assistência Social). A partir do golpe instituído em 2016 e da promulgação da Emenda Constitucional $95 / 16^{2}$ se assiste à negação da primazia do Estado na condução das políticas sociais brasileiras, voltando-se para a responsabilização da sociedade civil. Outra característica desse retrocesso se assenta no modo de gerir, deixando à mercê do voluntarismo a condução das políticas sociais nas estruturas governamentais nas três esferas de governo.

Nesse contexto, demarcado por avanços e retrocessos no campo da gestão das políticas sociais se insere o tema desse estudo, que reconhece a necessidade do debate da vigilância socioassistencial como condição essencial para o aprimoramento da gestão do SUAS, na medida em que capta, organiza, sistematiza informações da realidade social e dialoga com a capacidade de oferta das seguranças socioassistenciais ${ }^{3}$ e com os vazios protetivos. Adiciona-se a isso o impulsionamento de um modo de planejar e gerir essa política pública, superando as marcas históricas do voluntarismo e do amadorismo e, ao mesmo tempo, se distanciando do modelo clientelista que antagoniza com o que se pretende construir - gestões republicanas, federativas, democráticas e integradas que se conectam com as demandas sócio territoriais.

Além dos determinantes estruturantes postos acima, analisar a qualificação da gestão implica numa leitura dos modelos já desenhados pela administração pública brasileira que, a partir da Constituição Federal de 1988 (BRASIL, 1988), movimenta um pêndulo entre os seus ditames inspirados no estado social e as amarras da burocracia e

2 Altera as Disposições Constitucionais Transitórias e Novo Regime Fiscal com o objetivo de congelar por 20 anos o investimento nas políticas sociais (BRASIL, 2016b).

3 São consideradas seguranças socioassistenciais: Acolhida; Renda: Convívio ou vivência familiar; e Apoio e auxílio (BRASIL, 2012). 
do conservadorismo incrustrados nas entranhas da estrutura de gestão. A análise da vigilância socioassistencial, como um dos pilares do aprimoramento da gestão na política de assistência social, deve levar em consideração, além dos fatores macro estruturais já mencionados, a leitura da necessária institucionalidade; do profissionalismo; e do rigor republicano nas políticas setoriais no Brasil, cuja orientação advém das leis infraconstitucionais em vigor. Desse modo, nosso foco recai nas implicações da vigilância socioassistencial no Sistema Único de Assistência Social (SUAS), em especial, do papel propulsionador da instância estadual.

O conteúdo está organizado apontando inicialmente o contexto do SUAS e da vigilância socioassistencial, considerando seus marcos normativos e, em seguida, os resultados da pesquisa, cujo lócus foi a Secretaria de Estado de Desenvolvimento Humano do Estado da Paraíba, que agrega a gestão do SUAS. Desse modo, os dois primeiros itens são resultantes da busca bibliográfica e documental e, no terceiro tópico, constam os achados da pesquisa de campo realizada através de grupo focal ${ }^{4}$.

\section{O Contexto do SUAS: as bases analíticas para o estudo da vigilância socioassistencial}

O estudo sobre a vigilância socioassistencial no âmbito do SUAS nos remeteu à égide de sistemas únicos (a exemplo do SUS) que envolvem uma perspectiva de integração, uniformização e articulação de ações em todo o território nacional, imprimindo uma dimensão federativa e a necessária pactuação firmada em responsabilidades partilhadas e consubstanciada nos “Pactos de Aprimoramento" 5 . Esse modelo requer convergências mínimas em torno dos direitos e garantias a serem oferecidas por todos os entes federados.

Nos anos que sucederam a promulgação da Constituição Federal de 1988, portanto os anos 90, o debate sobre a capacidade de cumprir as diretrizes definidas para as políticas sociais, sobretudo a descentralização e a participação, passava pelas

\footnotetext{
${ }^{4}$ Esse artigo apresenta os resultados dos dados empíricos são referentes à compreensão e leitura dos sujeitos, assim não consta a análise dos documentos em nível estadual.

${ }^{5} \mathrm{O}$ pacto de aprimoramento tem sua base na estrutura federativa de responsabilidades compartilhadas autorizada pela Constituição Federal de 1988 e regulamentada nas leis infraconstitucionais como é o caso da LOAS (1993 e 2011). Além disso, no caso do SUAS também tem seu detalhamento referente à composição das Comissões Intergestores tripartite e Bipatite definidas na NOB 2005 (BRASIL, 2005) e NOB 2012 (BRASIL, 2012), tendo como base as competências de cada ente federado e a necessidade de construir espaços de decisão coletiva e pactuada.
} 
imperfeições do novo pacto federativo atingindo a redefinição de recursos e encargos e as dificuldades de construção de modelos integrados e unificados em todo o território nacional. Para Dain (1995), no lugar de pactos convergentes poderia haver tensões:

A descentralização passa a ser aleatória, sem correspondência entre assunção de responsabilidades pelos governos locais e a ampliação de transferências constitucionais a estados e municípios. Radicalizam-se também as tensões entre esferas de governo e a pressão local por recursos federais para o financiamento de uma política de necessidades básicas (DAIN, 1995, p.164).

Esse debate que se encontra entre as formulações constitucionais e normativas, seus preceitos e as possibilidades de implementação torna-se crucial, na medida em que as políticas sociais e os direitos por elas afiançadas devem ganhar concretude cotidiana e adentram a estrutura burocrática estatal, além de disputar uma nova concepção sobre sua pertinência que perpassa os operadores das políticas, os gestores, os seus destinatários e a sociedade em geral, colocando em contínuo a luta política por mais direitos.

Nessa linha, o sistema de proteção social não pode e não deve desprezar o contexto das lutas e organizações sociais e a história das conquistas que pautaram o Estado por políticas que ampliassem a seguridade social e, em especial, o reconhecimento da política de assistência social como garantidora de direitos e seguranças socioassistenciais ${ }^{6}$. Vale o destaque para as diretrizes de descentralização e participação, pois imprimem um novo modo de desenhar a gestão das políticas sociais. Reconhecendo, conforme aponta Nogueira (1997), que há diferença e distanciamentos entre democratizar e descentralizar. Para o autor a descentralização é um processo de cunho mais administrativo e a democratização depende de posição política e organização.

Descentralização e participação não são termos, e muito menos operações,
necessariamente complementares. Nem toda descentralização leva
automaticamente a maior participação. A descentralização pode ser imposta
estabelecida. A participação não, pois depende de fatores históricos-sociais e
de graus de amadurecimento político-ideológico e organizacional que muitas
vezes só aparecem após um longo período de tempo. (NOGUEIRA, 1997, p. 8)

\footnotetext{
${ }^{6}$ As seguranças e os direitos socioassistenciais foram definidos apenas com a emergência do SUAS em 2004 e reiteradas na NOB 2012, dispostas no seu art. $4^{\circ}$ - A colhida, renda, convívio familiar e comunitário, desenvolvimento e autonomia, apoio e auxílio (BRASIL, 2012).
} 
O modelo federativo prevê a tendência da descentralização, mas ao mesmo tempo, um importante processo de integração cooperativa entre os entes federados, destacando-se ações integradas nas três grandes funções que estruturam o SUAS (Proteção Social, vigilância socioassistencial e Garantia de Direitos). Desse modo, tanto as atuais regulamentações quanto os acordos firmados no âmbito das comissões intergetores preveem uma atuação e responsabilização para a implementação da vigilância socioassistencial. O Pacto federativo instalado e corporificado pelas agendas conjuntas das três instâncias governamentais expressam o desenho de gestão do estado brasileiro a partir da Constituição Federal de 1988. Naturalmente, por se tratar de instâncias de poder e comando, valem as definições de garantia de autonomia e interdependência necessárias para o estabelecimento de acordos e compromissos. Também emanam desse modelo federativo pactuado, as relações de cooperação e compromissos, sobretudo, no caso do aprimoramento do SUAS, que responsabilizam as esferas estaduais a apoiarem os municípios respondendo aos princípios de unidade, regras repartidas e autonomia das instâncias (federal, estadual e municipal).

A pertinência do trato do tema sobre o desenho federativo ${ }^{7}$ das políticas sociais, em especial do SUAS, se dá pelo fato de que a vigilância socioassistencial é de responsabilidade dos três entes federados e que a instância estadual tem importante papel, tanto na implantação e implementação em seu âmbito, reconhecendo as especificidades da desigualdade e desproteções em seu território, como no incentivo aos municípios para que desenvolvam a mesma função no seu escopo de atenção.

Nessa linha, a análise desses temas requer reflexões de aspectos estruturantes que emolduram a gestão das políticas sociais nos dias atuais e a intrínseca relação da vigilância socioassistencial com o conhecimento socioterritorial e o planejamento a colocam no cerne do aprimoramento gerencial e das provisões dessa política pública.

Se os sistemas protetivos necessitam dar respostas que potencializem os direitos afiançados pela Constituição Federal de 1988, há que se identificar em cada uma das políticas sociais, conforme dito por Silva, Yazbek e Di Giovani (2004) como direcionar esse olhar perguntando a quem se destina, como e quanto de proteção.

\footnotetext{
7 A CF 1988 define, em seu artigo 23, as responsabilidades comuns dos entes federados e nos capítulos III e IV que compreendem até o artigo 31 onde são apresentadas as responsabilidades específicas de cada ente (BRASIL, 1988).
} 
Assim, alguns elementos conjugam um caminho para a estruturação da vigilância socioassistencial como função dessa política a captura da realidade social com toda a sua complexidade, a direção protetiva que é necessária ser dada. Esse caminho traz como elemento mediador as seguranças socioassistenciais oferecendo concretude ao direito social que dá base primordial à Política de Assistência Social. Quando Berenice Couto (2004) afirma que o direito só pode ser reconhecido quando concretizado.

Os direitos, enquanto constitutivos de um patamar de sociabilidade, têm jogado papel importante na sociedade contemporânea que, ao discuti-los, coloca em xeque as formas de relação que são estabelecidas, tornando tenso o movimento por tê-los reconhecidos em lei, protegidos pelo Estado, e, mais do que isso, explicitados na vida dos sujeitos concretos. (COUTO, 2004, p. 37).

No entanto, no campo dos novos direitos afiançados pela concepção de Seguridade Social exarada na Constituição Federal de 1988, implicou em delimitar o campo de atenção dessa política pública. Há que se buscar formas de integrar os direitos previstos com as seguranças afiançadas.

Especificamente no que concerne às responsabilidades na gestão das políticas sociais cabe o destaque referente ao financiamento ${ }^{8}$, mas também às atribuições em suas provisões que estão detalhadas nas leis infraconstitucionais das políticas setoriais. No caso da política de assistência social e, em especial, da função de vigilância socioassistencial vamos apresentar no item que se segue. O presente estudo se concentra em especial na política de assistência social na organização de uma de suas funções: a vigilância socioassistencial.

Esse tema tem muitos entrelaçamentos vinculados às demais funções dessa mesma política e às suas provisões e também em relação à capacidade de apreender a realidade de desproteção e violação de direitos que impactam nas responsabilidades do Sistema Único de Assistência Social.

\footnotetext{
${ }^{8}$ Cabe destacar que o debate sobre o federalismo e seus pressupostos mais fundantes, como autonomia e interdependência, não pode desconsiderar o lugar central da divisão do fundo público, na medida em que esse aspecto impulsiona ou retrai a participação dos entes federados. Segundo a maioria dos autores que estudam o federalismo brasileiro apontam um descompasso entre as reponsabilidades (sobretudo das unidades subnacionais) e a sua capacidade de arrecadação.
} 


\section{Vigilância Socioassistencial - marco regulatório}

Nesse tópico, nossa intenção é trazer alguns pontos, descritos nos documentos normativos que contribuem para a compreensão do desenho da vigilância socioassistencial. Para tanto, é fundamental que se apresente seu lugar na estrutura do sistema, suas principais funções e temas com os quais dialoga, como sistema de informação, desigualdades territoriais, critérios e indicadores da rede de serviços e benefícios. Iniciamos o caminho pontuando as inovações do Sistema Único de Assistência Social e resgatando a vigilância socioassistencial na estrutura desse sistema. Posta como uma de suas três grandes funções ${ }^{9}$, a vigilância socioassistencial define um marco de aprimoramento e profissionalização da gestão.

Recorrer ao marco regulatório dessa função implica em identificarmos sua obrigatoriedade, sua centralidade e, ao mesmo tempo, chamar a atenção para o fato de que um número significativo de municípios brasileiros não a implantou, de forma institucional e integrada com as demais funções desse sistema, indicando déficit de implementação do SUAS. Soma-se a isso, as parcas iniciativas das instâncias estaduais em definirem ações de cooperação junto aos municípios nessa empreitada. Não é nossa intenção esgotar a análise dos documentos normativos, mas sim apontar os principais aspectos que balizarão nossa análise posterior.

A política de assistência social adotou, a partir de 2004, um modelo moderno e integrado de gestão desenhado a partir de um sistema único. Essa lógica, que dá organicidade à institucionalidade da política de assistência social em todo o território nacional, não prescindiu dos princípios e diretrizes que orientam as políticas sociais brasileiras, inscritos na Constituição Federal de 1988. Assim, coube aos desenhadores ${ }^{10}$ do SUAS contemplar um modelo que fosse descentralizado, participativo, de caráter

\footnotetext{
${ }^{9}$ São Funções da Política de Assistência Social: Proteção - que se desdobra em básica e especial; vigilância socioassistencial que pressupõe a análise territorial da proteção e desproteção afiançada por esse campo da seguridade social e indica a possibilidade de prevenção de agravos de vulnerabilidade e risco social; por fim, a função da defesa dos direitos que visa a garantir o pleno acesso aos direitos no conjunto das provisões socioassistenciais.

${ }^{10}$ É sempre fundamental lembrar que o SUAS foi escrito por muitas mãos a partir das deliberações da IV Conferência Nacional de Assistência Social, desse modo, ele já nasce democraticamente construído.
} 
universal $^{11}$, de responsabilidade primaz do Estado. Com esses princípios e diretrizes o SUAS tem uma base de sustentação em três grandes funções.

A estrutura de gestão da política de assistência social, firmada sob a égide de Sistema Único, instituída a partir de 2004, segue de forma acelerada alcançando quase $100 \%$ dos municípios brasileiros e a totalidade dos Estados. Esta realidade impingiu a necessidade de avaliar, cada vez e com maior precisão, o desenvolvimento deste Sistema. Não foi sem motivo que, tanto os processos avaliativos realizados no interior do Ministério de Desenvolvimento Social, com destaque para o Censo SUAS ${ }^{12}$, quanto os realizados pelo IBGE, apontaram para a necessidade de aprimoramento dos sistemas de gestão.

Há a premência em encontrar os caminhos de superação dos déficits de gestão na esfera pública, sobretudo na política de assistência social que guarda as especificidades relacionadas à sua trajetória histórica fora do Estado, o que implica na organização de nova estrutura administrativa e as ações e serviços adotados que trazem para dentro da estrutura pública atribuições complexas e diversificadas. A estrutura do SUAS prevê formas de gestão eficientes, eficazes e com efetividade social. Nesta linha, deve ter seu traçado articulando às diferentes esferas de governo, instituindo sistemas de informação que sustente as características de democratização da informação e todos os processos de monitoramento e avaliação.

À luz das orientações contidas nos estudos sobre aprimoramento da gestão, um campo que também necessita de ser aprofundado no SUAS é a identificação dos dados de realidade que sofrem intervenção da referida política pública. Para tanto, houve a necessidade de instituir como uma de suas funções a vigilância socioassistencial.

\footnotetext{
${ }^{11}$ Destaca-se que para a política de assistência, a LOAS/1993, reconhece a universalidade para "todos que dela necessitar" (BRASIL, 1993). Coube ao SUAS propor um modelo que abrangesse todo o território nacional e todos os cidadãos que estivessem desprovidos das seguranças previstas nessa política pública.

12 O Censo SUAS, definido e autorizado pelo Decreto No. 7.334/2010, se constituiu num importante instrumento de avaliação e monitoramento dos serviços, programas e benefícios ofertados pelo Sistema Único de Assistência Social (BRASIL, 2010). Tendo iniciado em 2007, sofreu aprimoramentos que, ao longo dos anos de sua implementação ampliou o escopo de informações colhidas por meio de questionários que são respondidos exclusivamente através de um aplicativo eletrônico. Além disso, o Censo SUAS é realizado anualmente pela Secretaria Nacional de assistência social e tem por objetivo monitorar e avaliar o estágio de desenvolvimento do SUAS em todo o território nacional, levando em conta as esferas estaduais e municipais.
} 


\begin{abstract}
A vigilância deve buscar conhecer o cotidiano das famílias, a partir das condições concretas do lugar onde vivem e não só as médias estatísticas ou números gerais, responsabilizando-se pela identificação dos "territórios de incidência" de riscos no âmbito da cidade, do Estado, do país, para que a assistência social desenvolva política de prevenção e monitoramento de riscos. (BRASIL, 2005, p. 20)
\end{abstract}

A atribuição de vigilância socioassistencial comporta precipuamente duas dimensões. São elas: a do estudo da realidade com foco na necessidade de proteção social, o que implica na identificação e conhecimento do público destinatário e o mapeamento da capacidade dos Órgãos Gestores nas três esferas de governo em conhecerem e identificarem sua capacidade de atenção. A NOB/SUAS a expressa como:

\begin{abstract}
O desenvolvimento da capacidade e de meios de gestão assumidos pelo órgão público gestor da Assistência Social para conhecer a presença das formas de vulnerabilidade social da população e do território pelo qual é responsável [...] detectar e informar as características e dimensões das situações de precarização que vulnerabilizam e trazem riscos e danos aos cidadãos, a sua autonomia, socialização e ao convívio familiar". (BRASIL, 2005, p. 20
\end{abstract}

Todas essas medidas se encontram num campo que necessita de aprimoramentos, pois demandam capacitação da esfera pública, especialmente no que concerne à gestão das políticas sociais. A Política Nacional de Assistência Social (PNAS), ao criar um sistema de gestão, instituiu também, uma nova rede de serviços e a articulou com os benefícios. Ao criar essa rede exigiu uma reflexão sobre as ações e as práticas profissionais. O monitoramento, pensado como instrumento de gestão, tem múltiplas dimensões que se referem ao financiamento, à execução, à organização gerencial, aos recursos humanos, dentre muitos outros aspectos. Pois, a adoção de práticas sistemáticas de acompanhamento está diretamente relacionada com o aprimoramento também sistemático e progressivo do SUAS (RIZZOTTI, 2010).

A avaliação da efetividade social das políticas sociais em geral e da assistência social em particular, deve levar em consideração a complexidade do seu objetivo, como o alargamento da proteção social dentro da esfera da seguridade social e, ainda, considerar as diretrizes postas como a capacidade de ampliar a participação social e a democratização da gestão. Muito embora a avaliação da necessidade para balizar a oferta de serviços e benefícios represente uma lógica mais igualitária, ainda há muita 
dificuldade no interior das políticas sociais de aprimorar seus sistemas de avaliação (TREVISAN; BELLEN, 2008). Além disso, associar ao objetivo de garantia de proteção social a outros princípios, que são mais amplos e respondem à lógica da organização social como um todo, como os de justiça social e democracia ainda está longe de apontar, de forma mais clara e objetiva, a contribuição das políticas sociais neste contexto.

Ao longo do processo de institucionalização do SUAS, as regulações emitidas a partir de grandes negociações entre o Estado e a Sociedade Civil nos diferentes espaços de pactuação e deliberação, foram se aprimorando e trazendo especificidades para o campo da Vigilância Socioassistencial, dentre elas se destacam os objetivos previstos no Art. 87 da NOB/SUAS 2012, avultando a sua função na prevenção de riscos e vulnerabilidades, o que contempla a atenção na realidade social e na qualidade de oferta dos serviços (BRASIL, 2012). Nesse sentido, a vigilância socioassistencial deve ocupar um lugar na estrutura da gestão e estabelecer a intersecção entre o cotidiano dos serviços (leitura dos territórios e provisões do SUAS) e o planejamento.

Ao ser posta como uma das funções do SUAS, conforme inscrito na PNAS (2004), a vigilância socioassistencial, reconhece a necessidade premente de se construir um sistema de informação que respeitasse um padrão de dados e indicadores capazes de subsidiar a gestão dessa política pública, os padrões dos serviços; e ainda indica a necessidade de ter a dimensão do território como forma de organizar e sistematizar as informações, assim dito:

Vigilância socioassistencial - refere-se à produção, sistematização de informações, indicadores e índices territorializados das situações de vulnerabilidade e risco pessoal e social que incidem sobre famílias/pessoas nos diferentes ciclos (criança e adolescentes, adultos e idosos) pessoas com a redução de capacidade pessoal com deficiência ou em abandono; crianças e adultos vítimas de formas de exploração, de violência e de ameaças; vítimas de preconceito por etnia, gênero e opção pessoal; vítimas de apartação social que lhes impossibilite sua autonomia e integridade, fragilizando sua existência; vigilância sobre os padrões de serviços de assistência social em especial aqueles que operam na forma de albergues, abrigos, residências, semi-residências, moradias provisórias para os diversos segmentos etários. Os indicadores a serem construídos devem mensurar no território as situações de riscos sociais e violação de direito (BRASIL, 2004, p. 39-40).

Essa definição expressa, nesse primeiro documento, expressa a gênese de todo um processo de construção de um sistema nacional de informação que permitiu, pela 
primeira vez, fazer o registro das ações, provisões e dados das demandas e ofertas da política de assistência social - uma política nova, com nova estrutura, que traz para dentro da esfera pública e estatal informações antes invisíveis. Ao longo dos anos que se sucederam o SUASWEB ${ }^{13}$ sofreu importantes aprimoramentos adensados pela instituição do CensoSUAS.

A previsão de organização da vigilância socioassistencial com um lugar definido na estrutura do SUAS nas três esferas de governo está prevista na NOB/2012, que define uma seção especial para vigilância e, nesse campo, demarca como se caracteriza e se materializa o trato das informações e do monitoramento. Esse detalhamento se fez necessário pelo estágio de aprimoramento do SUAS por ocasião da edição dessa NOB, cuja perspectiva foi a de dar operacionalidade à vigilância. Algumas ações devem contar do escopo de suas responsabilidades ações e rotinas em, pelo menos, três dimensões diferentes e que se completam: Diagnóstico - destaca o uso de banco de dados, incluindo o Cadúnico e demais fontes de informações, cadastros dos serviços, etc. e elaboração de uma leitura territorial com destaque para a realidade de cada região, com atualização do sistema de; Planejamento - contribuir na elaboração dos processos de planificação em qualquer nível de governo e, sobretudo, nos Planos Anuais que devem ser realizados da forma mais democrática possível; e Monitoramento - que deve incluir acompanhamento da oferta de serviços (organização de dados de incidências, de notificações compulsórias) de modo a fomentar avaliações e mudanças nos rumos das ações se e quando necessárias.

Está intrínseca à estruturação da vigilância socioassistencial: a produção de informação sobre a realidade social, no que tange ao campo protetivo da política de assistência social; a produção de banco de dados sistematizados; e o apoio à gestão e ao aprimoramento dos serviços. Assim, na NOB-SUAS/2012, a vigilância socioassistencial aprofunda o conhecimento produzido, de forma sistematizada e continuado, dos territórios e a qualidade da oferta de serviços:

I - Das situações de vulnerabilidade e risco que incidem sobre famílias e indivíduos e dos eventos de violação de direitos em determinados territórios;

II - Do tipo, volume e padrões de qualidade dos serviços ofertados pela rede socioassistencial. (BRASIL, 2012, p. 40).

\footnotetext{
${ }^{13}$ Informações disponíveis em http://mds.gov.br/sistemas/sistemas-1.
} 
Alguns desdobramentos que decorrem dessa orientação merecem um olhar mais apurado, o primeiro deles a compreensão dos aspectos da vulnerabilidade e violações de direito que incidem sobre as responsabilidades de provisões do SUAS e outra é o aprofundamento da leitura do território circunscrita no conceito de desigualdade social com diferentes agravos e configurações nos diferentes territórios. Na atualização da LOAS em 2011 a vigilância socioassistencial apresenta como objetivo, descritos no art. $2^{\circ}$ "II - a vigilância socioassistencial, que visa a analisar territorialmente a capacidade protetiva das famílias e nela a ocorrência de vulnerabilidades, de ameaças, de vitimizações e danos" (BRASIL, 2011).

A implementação da vigilância socioassistencial, com base nesses objetivos, permite a concretização de seu campo estruturante a partir de conhecimentos aprofundados das demandas de violações dos direitos e seguranças socioassistenciais, assim como da necessidade de proteção territorializada. A gestão nos três níveis de governo pode e deve se ancorar nas informações produzidas e insumos que permitem a construção de isonomias (traço da gestão republicana) para a gestão que pressupõe os indicadores de atingimento de objetivos e metas para a definição de padrão de financiamento, tipo, volume, localização e qualidade das ofertas e das condições de acesso - características e distribuição da rede de proteção. Trata-se, portanto, de um processo de aperfeiçoamento da gestão e da oferta de serviços, na medida em que aprimora o planejamento, a execução, o monitoramento e a avaliação do SUAS.

Desse modo, não se pode aprofundar o tema da função da vigilância socioassistencial sem olhar para os nexos entre as determinações históricas e econômicas e o cotidiano dos territórios e dos sujeitos. Essa visão permite a ampliação da atenção individual para uma perspectiva coletiva, o que também incide sobre o modo e a organização da oferta dos serviços. Além disso, é fundamental articular à leitura estrutural as especificidades da desproteção das diferentes políticas sociais que incidem sobre a vulnerabilidade e violações de direitos dos moradores de um determinado território.

A vigilância socioassistencial, entendida para além de uma ferramenta, um setor ou um conjunto de informações é função a ser cumprida na gestão da política de assistência social, e, portanto, necessita prover respostas específicas às demandas, em articulação com as funções de Proteção Social e de Defesa dos Direitos. (BRASIL, 2013, p. 22) 
Naturalmente a leitura da realidade social que instrui a vigilância deve ser abrangente, considerando suas múltiplas dimensões, conforme nos instrui as autoras do livro o SUAS em movimento, que faz uma análise do grau de institucionalidade do SUAS, com dados colhidos nos seus primeiros anos de implantação.

Evidenciam-se condições de pobreza e vulnerabilidade associadas a um quadro de necessidades objetivas e subjetivas, nas quais se somam necessidades materiais, relacionais, culturais que interferem na reprodução social dos trabalhadores e de suas famílias. Trata-se de uma concepção multidimensional de pobreza que não se reduz às provações materiais, alcançando diferentes planos e dimensões da vida do cidadão (COUTO; RAICHELIS; YAZBEK, 2010, p. 40).

Com essa compreensão quanto à capacidade da vigilância socioassistencial em apreender, de forma aprofundada, a realidade social de vulnerabilidade, desproteções e potencialidade é possível considerar o modo articulado e integrado de construção dessa função, exigindo a participação dos diferentes atores (população usuária, trabalhadores e gestores), impetrando seu modo democrático.

Um dos aspectos em processo de aprimoramento no SUAS é sua capacidade de reconhecer as diferenças territoriais que se configuram não apenas como diferentes regiões, mas também como: (i) a densidade populacional nos municípios que acaba por diferenciar a institucionalidade da gestão dessa política e, por conseguinte, do modo de seu funcionamento tanto na gestão como na oferta de serviços e benefícios; (ii) o mundo rural e urbano, que apresentam diferentes modos de vida e realidade de acesso aos bens e serviços, também as diferenças dos bairros mais periféricos, cuja condição de vida e o direito à cidade, muitas vezes evidencia um importante elemento de apartamento; (iii) diferentes povos e grupos populacionais (índios, quilombolas, ribeirinhos, negros, LGBT, idosos, pessoas com deficiência, crianças e adolescentes, dentre outros), em especial a necessidade de compreender o modo como se expressam para esses grupos as violações de direitos, as desigualdades. Esses são apenas alguns dos aspectos que passaram a figurar como essenciais para tornar o SUAS mais equitativo.

A relação território/vulnerabilidade/ofertas do SUAS esteve presente em todos os seus documentos e nos processos conferenciais, sobretudo naqueles que avaliaram 
ou pautaram o desenvolvimento do SUAS. Alguns desses momentos como a 4 a Conferência Nacional apontava: "Construir uma agenda para 2004, para que, sob a coordenação do Ministério da Assistência Social, seja implantado/implementado o Sistema Único de Assistência Social - SUAS de forma descentralizada, regionalizada e hierarquizada, com base no território" (BRASIL, 2016a). Essa preocupação com a ampliação do acesso ao SUAS que considerou, além do aumento quantitativo da oferta e serviços, a necessidade de reconhecimento da diversidade territorial, dos povos, grupos e aspectos de ordem cultural, histórica etc. apareceu fortemente no II Plano Decenal aprovado pelo Conselho Nacional de Assistência Social no início de $2016^{14}$. Pode-se constatar alguns momentos, que a escrituração do referido Plano destaca os aspectos regionais, sobretudo em seu posicionamento inicial: A Assistência Social acessível a todos (as) os (as) brasileiros (os), considerando as diversidades e especificidades de públicos e territórios, é o horizonte que se projeta para orientar a próxima década (BRASIL, 2016c).

Se de um lado, a estruturação dessa função (vigilância socioassistencial) exige o conhecimento da realidade de desproteção e vulnerabilidade dos territórios, de outro lado necessita circunscrever sua leitura às provisões do espectro da Política de Assistência Social. Desse modo, é fundamental considerar como parâmetro as seguranças socioassistenciais previstas nos documentos normativos, sobretudo sua edição posta na NOB/2012.

Depreende-se que não é possível falar de vigilância socioassistencial sem se ater ao conjunto de ações que permitam caracterizar a realidade social identificando as desproteções e, por outro, adotar as seguranças como parâmetro para balizar e dar direção sobre o escopo e campo de responsabilidade protetiva da política de assistência social e organizar o olhar e a direção no campo protetivo do SUAS.

Dois pontos importantes estão destacados aqui, referindo-se à produção e sistematização de dados de especificidades locais e a sua utilização pelos trabalhadores e gestores do SUAS, de modo a aprimorar o tipo de oferta dessa política pública.

\footnotetext{
${ }^{14}$ O II Plano Decenal foi formulado após amplo de debate em todo o processo conferencial de 2016 com os 5570 municípios e 27 estados da federação, além de construir diretrizes a partir do debate dos 5 encontros regionais e 1 nacional dos Gestores Municipais e do Encontro Nacional dos Gestores Estaduais. Despois desse profundo processo participativo foi aprovado no início de 2016 pelo Conselho Nacional de Assistência Social. (BRASIL, 2016c).
} 
Naturalmente esse caminho de aprimoramento chama à cena um amplo estudo sobre indicadores de conhecimento da realidade local, em especial dos déficits de desproteção e também de monitoramento e avaliação da rede de serviços. Esse tema nos remete aos estudiosos, dentre eles Paulo Jannuzzi (2001), que reconhece como caminho para aprimoramento da avaliação a definição de indicadores. Assim, se pronuncia o autor ao definir indicador: "É um recurso metodológico, empiricamente referido, que informa algo sobre um aspecto da realidade social ou sobre mudanças que estão se processando na mesma." (JANNUZZI, 2001, p. 15). Desse modo, espera-se que os Órgãos gestores da política de assistência social tenham em sua estrutura um setor destinado à vigilância socioassistencial com a designação de equipe técnica especializada, infraestrutura adequada e devidamente orientada por regulação descrita em lei. Segundo o art. 90 NOB 2012.

\footnotetext{
União, os Estados, o Distrito Federal e os Municípios devem instituir a área da Vigilância socioassistencial diretamente vinculada aos órgãos gestores da política de assistência social, dispondo de recursos de incentivo à gestão para sua estruturação e manutenção. Parágrafo único. A Vigilância socioassistencial constitui como uma área essencialmente dedicada à gestão da informação, comprometida com: I - o apoio efetivo às atividades de planejamento, gestão, monitoramento, avaliação e execução dos serviços socioassistenciais, imprimindo caráter técnico à tomada de decisão; II - a produção e disseminação de informações, possibilitando conhecimentos que contribuam para a efetivação do caráter preventivo e proativo da política de assistência social, assim como para a redução dos agravos, fortalecendo a função de proteção social do SUAS (BRASIL, 2012)
}

Destaca-se que a política de assistência social tem produzido inúmeros dados, dentre eles ressalta-se o Cadastro Único, Prontuário SUAS e o Censo SUAS. A sistematização e organização dessas informações implicam em zelo (qualidade, periodicidade, veracidade dos dados), tanto na inclusão de dados nos sistemas nacionais e regionais, como a guarda e o sigilo. Além disso, podem e devem permitir uma cultura de busca de informações dando consistência às decisões tomadas no âmbito dessa política pública. A Vigilância socioassistencial, enquanto uma função da Política de Assistência Social, registra a premência na elaboração de diagnósticos interpretativos que discirnam a realidade social com as demandas por proteção social presentes nos territórios, assim como suas potencialidades. 


\section{A trajetória de Implantação e os Desafios a partir do Olhar dos Operadores da Vigilância Socioassistencial na SEDH/Paraíba}

Este tópico se dedica ao modo como os profissionais que ocupam funções de gestão compreendem a Vigilância socioassistencial na esfera estadual. No entanto, antes de apresentar alguns fragmentos desses achados vale trazer algumas informações sobre a pesquisa, que incluiu, além do estudo bibliográfico e normativo expostos resumidamente dos itens acima, também fez busca e estudos documentais e empíricos junto aos profissionais que atuam na área ${ }^{15}$.

A pesquisa iniciou em 2018 com o financiamento do CNPq e da Fapesq ${ }^{16}$, compondo estudo sobre a vigilância socioassistencial e gestão do trabalho (este segundo tema ainda em fase de finalização). A escolha do lócus da pesquisa SEDH/Paraíba - se deu por ser um dos estados que instalou logo de início a gerência de Vigilância socioassistencial e, dentre outras medidas, elaborou um sistema próprio informatizado de coleta de dados, favorecendo a leitura continuada e sistematizada de informações para dar suporte a todas as ações, incluindo o financiamento e o planejamento e apoio técnico aos municípios. Outro aspecto importante em relação à escolha desse lócus é a forma como a SEDH/Paraíba se relaciona com os municípios na perspectiva de incentivar a implementação da vigilância socioassistencial na esfera estadual. Esses aspectos serão ressaltados na apresentação das análises a seguir, cujos dados foram colhidos a partir do grupo focal realizado com técnicos e diretores da Secretaria de Estado de Desenvolvimento Humano da Paraíba (SEDH) que acolhe uma gerência específica para essa função.

O grupo focal, realizado com gestores ${ }^{17}$, tratou centralmente sobre a implementação da vigilância socioassistencial na Paraíba e fez o contraponto com os aspectos normativos referentes a: obrigações da esfera estatal, mecanismos da coleta de informações implantados pela SEDH; relação com os municípios e o papel

\footnotetext{
${ }^{15}$ As informações detalhadas sobre os documentos da esfera estadual analisadas constam do relatório parcial da pesquisa apresentado em 2019.

${ }^{16}$ Fundação de Apoio à Pesquisa do Estado da Paraíba.

17 Participaram do grupo focal gerentes da Secretaria de Estado de Desenvolvimento Humano das seguintes áreas: Vigilância socioassistencial; Proteção Social Especial; Proteção Social Básica e a servidora que exerceu o cargo de da Vigilância socioassistencial por ocasião de sua implantação.
} 
impulsionador dessa função; os principais desafios. Destaca-se, a seguir, alguns pontos do diálogo com o grupo.

No que concerne aos objetivos e às funções da Vigilância foi notória a incidência na produção e organização de dados, indicadores e informações que expressassem as situações de precarização da condição de vida de forma territorializada, tendo como foco o reconhecimento das condições de risco e da violação de direitos e desproteções, subsidiando o caráter preventivo no SUAS. Além disso, observa-se o domínio das informações da rede socioassistencial instalada no território, com o paralelo entre oferta e demanda das provisões da política de assistência social.

Ao tratar da motivação da SEDH, no que concerne à operação da Vigilância socioassistencial, percebe-se uma ancoragem com o aprimoramento da gestão, construindo caminhos para superar todo o tipo de amadorismo e voluntarismo que marcou essa política pública ao longo de sua história. Ressalta o aprimoramento do processo com a instalação do sistema integrado com os municípios, identificando as violações de direitos nos diferentes territórios. Esse processo seguia um rastro de lacunas não contempladas nos registros do MDS. Desse modo, dados coletados foram cada vez mais subsidiando o processo de monitoramento continuado e integrado aos municípios.

A ação cooperada com os municípios inclui estratégias dialogadas e o assessoramento a partir dos dados que desvendam e permitem interpretação da realidade. Em relação à adesão dos municípios, a centralidade do tema da vigilância também pode ser sentida com várias capacitações sobre o tema. Soma-se a esse modo de sensibilização, a associação do cofinanciamento do estadual, sobretudo, no que concerne à rede de proteção especial.

Outro elemento facilitador se estabeleceu pelo preenchimento dos relatórios (cibernéticos) com maior adesão no sistema estadual, pois representa melhor a realidade deles e mais amigável aos técnicos. O Registro e a sistematização de dados é algo recente na política de assistência social, construindo a partir de 2004, com a instalação do SUASWEB e, nas esferas estaduais, a proposição é ainda mais tardia. Desse modo, os trabalhadores do SUAS necessitam construir uma nova cultura de uso dos dados e de planejamento. 
Vale destacar o enfoque na realidade regional, reconhecendo as diferenças das regiões da Paraíba. A perspectiva territorial permite à aproximação com a população e a realidade local e, com isso a compreensão do espaço/acesso no processo de alocação e adequação dos serviços, pois aproxima a leitura da vulnerabilidade, desproteção, violação e direitos, assim como identifica as forças e resistências de cada território.

A gestão do SUAS na SEDH/Paraíba, ao adotar a lógica territorial como um de seus pressupostos de gestão, o fez na perspectiva de aprimorar o conhecimento da realidade social; de melhorar o acesso dos destinatários aos serviços e benefícios; de favorecer a articulação da rede de serviços; de potencializar a intersetorialidade como estratégia de gestão; de possibilitar a integração entre serviços e benefícios; e de aprofundar e materializar processos participativos.

A construção dessa nova forma de gestão tem recebido diferentes incentivos, que vão desde financeiro (repasse calculado pelos dados inseridos no sistema, condições objetivas), até a formação e o convencimento sobre a importância de apropriação da realidade social onde se atua. A possível integração dos sistemas é um elemento facilitador da implantação da vigilância socioassistencial. A federalização da política de assistência social também depende de avanços na integração dos sistemas de informação com uma mínima padronização e fluxo rápido dos dados.

A partir das categorias adotadas nesse estudo foi possível identificar:

- um conjunto de conhecimentos referentes ao tema da gestão no âmbito das políticas sociais e em especial do Sistema Único de Assistência Social;

- a estrutura e funcionamento da gestão do SUAS no âmbito da Secretaria de Estado do Desenvolvimento Humano no que tange à implantação da vigilância socioassistencial.

- indicadores que evidenciem a relação de corresponsabilidade entre a instância estadual e municipais na Paraíba, tendo como pressuposto as diretrizes de gestão de políticas sociais previstas na Constituição Federal de 1988 e as normativas definidas na circunscrição do SUAS.

A implementação e o aprimoramento da Vigilância socioassistencial têm imposto aos entes federados uma nova forma de se relacionar com a compreensão das desigualdades territoriais e a violação de direitos. A necessidade de registro, de 
padronização passou a exigir o aprofundamento de conceitos fundantes para o SUAS. Além disso, também a necessidade de construir sistemas informatizados que respondam à grande complexidade desta política pública.

\section{Considerações finais}

O estudo empreendido realizou aproximação do modo como a instância estadual oferece apoio aos municípios no que se refere aos processos de gestão, em especial, no tocante à vigilância socioassistencial, reconhecendo os avanços necessários ao atual estágio de implementação da política de assistência social.

A dimensão política, que expressa as contradições intrínsecas do modelo capitalista, também se ancora a premente necessidade da restauração e manutenção da ordem democrática. Desse modo, os muitos movimentos sociais que têm pautado o Estado Brasileiro por um novo patamar civilizatório e de direitos se mantêm ativos na luta pela implantação de novos modelos protetivos para responderem às demandas já existentes que se ampliavam e se modificam. Destaca-se o momento atual de retrocesso na esfera nacional em seu compromisso com a garantia de direitos tem exigido esforço ainda mais intenso no sentido de resistir aos desmontes em curso.

$\mathrm{Na}$ história das políticas sociais não se tem arrego nas lutas por direitos. Sua história demonstrou os movimentos sociais, que haviam despontado no final do ciclo militar, aceleravam-se, intensificando sua atuação nos primeiros anos da Nova República. O envolvimento da sociedade civil nas lutas de reivindicação protagonizadas pelos movimentos organizados, emprestava-Ihes ainda mais legitimidade, alçando à posição privilegiada a expressão das demandas sociais da população. (RIZZOTTI, 2017).

Esse processo contínuo e dialético de lutas sociais firmadas no cotidiano e, ao mesmo tempo, nos ideários de democracia, liberdade e direitos, antes e depois da promulgação da Carta Constitucional, desenha uma proposta de política social e, por conseguinte, de seu gerenciamento. Nessa linha, os modelos de gestão, assim como seu aprimoramento têm nexos intrínsecos com o contexto histórico, econômico e social do país e sofrem modificações a depender das demandas e dos projetos em disputa.

As políticas sociais brasileiras passaram a ter novo marco orientador a partir da Constituição Federal de 1988, iluminado pelo pela direção do Estado Social. No Suas a perspectiva equidade no acesso, descentralização e participação indicou, direções: 
ideopolítica; normativa e organizativa; e aprimoramento, tanto da oferta da rede de serviços e de benefícios, como da estruturação qualificada da gestão. Esse novo caminho, ao impor responsabilidades públicas, exigiu novas configurações das estruturas governamentais nas três esferas de governo, tendo como destaque nesse estudo a vigilância socioassistencial.

Pensar prospectivamente os rumos da política de assistência social implica em se ancorar nos conhecimentos produzidos, processados e disponibilizados por um sistema de informação moderno e integrado, na celeridade de organização de financiamento que considere a transparência das informações e os critérios de qualidade da prestação de serviços e gestão.

Os protocolos adotados na gestão, além de construir os caminhos para o efetivo conhecimento desta política, têm sido usados num processo contínuo de aprimoramento da gestão do SUAS. Este aspecto torna-se essencial no estágio de implantação deste novo desenho organizativo. A avaliação da efetividade social das políticas sociais em geral e da assistência em particular deve levar em consideração a complexidade do seu objetivo como o alargamento da proteção social dentro da esfera da seguridade social e deve, ainda, considerar as diretrizes postas como a capacidade de ampliar a participação social e a democratização da gestão.

Os resultados da pesquisa têm construído uma análise do processo de gestão do Sistema Único de Assistência Social, permitindo o uso dos seus achados, tanto para o aprimoramento da gestão dessa e de outras políticas sociais, como no escopo da academia, aprofundando o tema em diferentes núcleos e grupos de pesquisadores. Desse modo, a contribuição desse artigo pode e deve ser posta em debates por diferentes matizes e compreensões para que se alarguem os horizontes do estudo da gestão de políticas sociais e da intrínseca necessidade do domínio do conhecimento da realidade.

\section{Referências}

BRASIL. [Constituição (1988)]. Constituição Federal de 1988. Brasília, DF: Senado Federal, 1988

BRASIL. Caderno do CapcitaSUAS 3 vigilância socioassistencial. Brasília, DF: MDS, 2013. 
BRASIL. Curso de atualização em vigilância socioassistencial do SUAS. Brasília, DF: MDS, 2016a.

BRASIL. Decreto no 7.334, de 19 de outubro de 2010. Institui o Censo do Sistema Único de Assistência Social - Censo SUAS, e dá outras providências. Brasília, DF: Presidência da República, 2010. Disponível em: http://www.planalto.gov.br/ccivil_03/_ato20072010/2010/decreto/d7334.htm\#: :text=DECRETO\%20N\%C2\%BA\%207.334\%2C\%20DE \%2019,vista\%20o\%20disposto\%20nos\%20arts. Acesso em: 3 set. 2020.

BRASIL. Emenda Constitucional no 95, de 2016. Altera o Ato das Disposições Constitucionais Transitórias, para instituir o Novo regime Fiscal, e dá outras providências. Brasília, DF: Câmara dos Deputados, 2016b. Disponível em: https://www2.camara.leg.br/legin/fed/emecon/2016/emendaconstitucional-95-15dezembro-2016-784029-publicacaooriginal-151558-pl.html. Acesso em: 3 set. 2020.

BRASIL. II plano decenal da assistência social (2016/2016): proteção social para todos/as os/as brasileiros/as: parte 1. Brasília: MDS, 2016c.

BRASIL. Lei no 8.742, de 7 de dezembro de 1993. Dispõe sobre a organização da Assistência Social e dá outras providências. Brasília, DF: Presidência da República, 1993. Disponível em: http://www.planalto.gov.br/ccivil_03/leis/l8742.htm. Acesso em: 3 set. 2020.

BRASIL. Lei no 12.435, de 6 de julho de 2011. Altera a Lei no 8.742, de 7 de dezembro de 1993, que dispõe sobre a organização da Assistência Social. Brasília, DF: Presidência da República, 2011.

BRASIL. Norma operacional básica. Brasília, DF: MDS, 2005.

BRASIL. Norma operacional básica. Brasília, DF: MDS, 2012.

BRASIL. Política nacional de assistência social. Brasília, DF: MDS, 2004.

COUTO, B. R. O direito social e a assistência social na sociedade brasileira: uma equação possível? São Paulo: Cortez, 2004.

COUTO, B. R.; YAZBEK, Maria Carmelita; RAICHELIS, Raquel. A Política Nacional de Assistência Social e o Suas: apresentando e problematizando fundamentos e conceitos. In: COUTO, Berenice Rojas; YAZBEK, Maria Carmelita; SILVA, Maria Ozanira da Silva e; RAICHELIS, Raquel (orgs.). O Sistema Único de Assistência Social no Brasil: uma realidade em movimento. São Paulo: Cortez, 2010.

DAIN, S. Experiência Internacional e especificidade brasileira. In: AFFONSO, R. de B.A., SILVA, P. L. B., org. Reforma tributária e federação. São Paulo: Editora UNESP, !995.

FERNANDES, F. A revolução burguesa no Brasil: ensaio de interpretação sociológica. Rio de Janeiro: Zahar, 1975.

JANNUZZI, P. Indicadores sociais no Brasil: conceitos, fontes de dados e aplicações. Campinas: Alínea, 2001. 
NOGUEIRA, M. A. A dimensão política da descentralização participativa. Revista São Paulo em Perspectiva, São Paulo, v. 1, n. 3, 1997.

RIZzOTTI, M. L. A. Política de assistência social e a construção dos sujeitos políticos: uma análise dos Conselho Municipais na região da AMEPAR. Latvia: Novas Edições Acadêmicas, 2017.

RIZZOTTI, M. L. A. Sistema único de assistência social: os caminhos de sua implantação sob a ótica do órgão gestor nacional. 2010. Relatório (Pós-Doutorado) - Pontifícia Universidade Católica de São Paulo, São Paulo, 2010.

SILVA, M. O. da S. e; YASBEK, M. C.; DI GIOVANI, G.. A política social brasileira no século XXI: prevalência dos programas de transferência de renda. São Paulo: Cortez, 2004.

TREVISAN, A. P; BELLEN, H. M. Avaliação de políticas públicas: uma revisão teórica de um campo em construção. Revista de Administração Pública, Rio de Janeiro, maio/jun. 2008. 